\title{
Study of Sliding Mode Control of Dc-Dc Buck Converter
}

\author{
Hanifi Guldemir \\ Technical Education Faculty, University of Firat, Elazig, Turkey \\ E-mail: hguldemir@firat.edu.tr \\ Received January 23, 2011; revised March 2, 2011; accepted March 15, 2011
}

\begin{abstract}
In this paper, a robust sliding mode controller for the control of dc-dc buck converter is designed and analyzed. Dynamic equations describing the buck converter are derived and sliding mode controller is designed. A two-loop control is employed for a buck converter. The robustness of the sliding mode controlled buck converter system is tested for step load changes and input voltage variations. The theoretical predictions are validated by means of simulations. Matlab/Simulink is used for the simulations. The simulation results are presented. The buck converter is tested with operating point changes and parameter uncertainties. Fast dynamic response of the output voltage and robustness to load and input voltage variations are obtained.
\end{abstract}

Keywords: Switched-Mode Power Supplies, Buck Converter, Dc-Dc Converter, Sliding Mode Control

\section{Introduction}

Electronic power converters are used as an actuator for electromechanical systems. The buck type dc-dc converters are used in applications where the required output voltage is lower than the source voltage. Different control algorithms are applied to regulate dc-dc converters to achieve a robust output voltage. As dc-dc converters are nonlinear and time variant systems, the application of linear control techniques for the control of these converters are not suitable. In order to design a linear control system using classical linear control techniques, the small signal model is derived by linearization around a precise operating point from the state space average model [1]. The controllers based on these techniques are simple to implement however, it is difficult to account the variation of system parameters, because of the dependence of small signal model parameters on the converter operating point [2]. Variations of system parameters and large signal transients such as those produced in the start up or against changes in the load, cannot be dealt with these techniques. Multiloop control techniques, such as current mode control, have greatly improved the dynamic behavior, but the control design remains difficult especially for higher order converter topologies [3].

A control technique suitable for dc-dc converters must cope with their intrinsic nonlinearity and wide input voltage and load variations, ensuring stability in any operating condition while providing fast transient response. Since switching converters constitute a case of variable structure systems, the sliding mode control technique can be a possible option to control this kind of circuits [4]. The use of sliding mode control enables to improve and even overcome the deficiency of the control method based on small signal models. In particular, sliding mode control improves the dynamic behavior of the system, and becomes very useful when the system is required to operate in the presence of significant unknown disturbances and plant uncertainties [5].

In order to obtain the desired response, the sliding mode technique changes the structure of the controller in response to the changing state of the system. This is realized by the use of a high speed switching control forcing the trajectory of the system to move to and stay in a predetermined surface which is called sliding surface. The regime of a control system in the sliding surface is called Sliding Mode. In sliding mode a system's response remains insensitive to parameter variations and disturbances [6]. Unlike other robust schemes, which are computationally intensive linear methods, analogue implementations or digital computation of sliding mode is simple.

\section{The Mathematical Model of Dc-Dc Boost Converter}

The topology of a buck converter is shown in Figure 1. When the switch is on position 1 the circuit is connected to the dc input source resulting an output voltage across the load resistor. If the switch changes its position to position 0 , the capacitor voltage will discharge through the load. Con- 


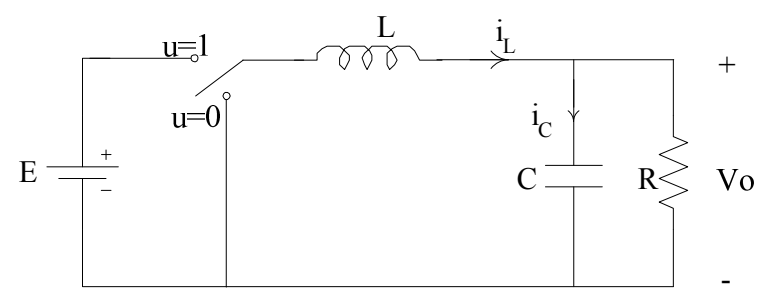

Figure 1. The buck converter.

trolling switch position the output voltage can be maintained at a desired level lower than the input source voltage.

The buck converter shown in Figure $\mathbf{1}$ can be described by the following set of equations

$$
\begin{aligned}
& L \frac{\mathrm{d} i_{L}}{\mathrm{~d} t}=u E-V_{o} \\
& C \frac{\mathrm{d} v_{o}}{\mathrm{~d} t}=i_{L}-i_{o}
\end{aligned}
$$

where $i_{L}$ is the inductor current, $V_{o}$ is the output capacitor voltage, $E$ is the constant external input voltage source, $L$ is the inductance, $C$ is the capacitance of the output filter and $R$ is the output load resistance. $u$ is the control input taking discrete values of 0 and 1 which represents the switch position.

$$
u=\left\{\begin{array}{l}
0 \text { if switch is at position } 0 \\
1 \text { if switch is at position } 1
\end{array}\right.
$$

It is assumed here that the inductor current will have a nonzero value due to load variations which is known as the continuous conduction mode (CCM). Figure 2 shows the current and voltage in continuous conduction mode.

Rewriting Equations (1) and (2) in the form of state equations by taking the inductor current and output capaci-

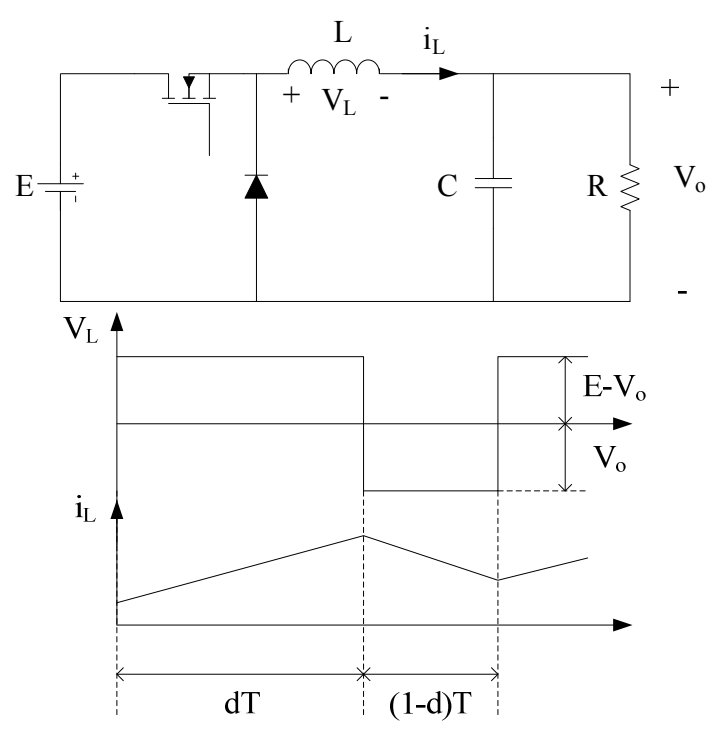

Figure 2. Topology of buck converter and current. tor voltage as the states of the system, the following state equations are obtained.

$$
\begin{aligned}
\frac{\mathrm{d} i_{L}}{\mathrm{~d} t} & =\frac{E}{L} u-\frac{V_{o}}{L} \\
\frac{\mathrm{d} V_{o}}{\mathrm{~d} t} & =\frac{i_{L}}{C} u-\frac{V_{o}}{R C}
\end{aligned}
$$

where

$$
i_{0}=\frac{V_{o}}{R}
$$

The block diagram of the buck converter using state Equations (4) and (5) is shown in Figure 3.

\section{Sliding Mode Control}

The sliding mode provides a method to design a system in such a way that the controlled system is to be insensitive to parameter variations and external load disturbances [7-10]. The technique consists of two modes. One is the reaching mode in which the trajectory moves towards the sliding line from any initial point. In reaching mode, the system response is sensitive to parameter uncertainties and disturbances. The other is the sliding mode in which, the state trajectory moves to origin along the switching line and the states never leave the switching line. During this mode, the system is defined by the equation of the switching surface and thus it is independent of the system parameters.

The Variable Structure System (VSS) theory has been applied to nonlinear systems [11]. One of the main features of this method is that one only needs to drive the error to a switching surface, after which the system is in sliding mode and robust against modeling uncertainties and disturbances. A Sliding Mode Controller includes several different continuous functions that map plant state to a control surface, and the switching among different functions is determined by plant state that is represented

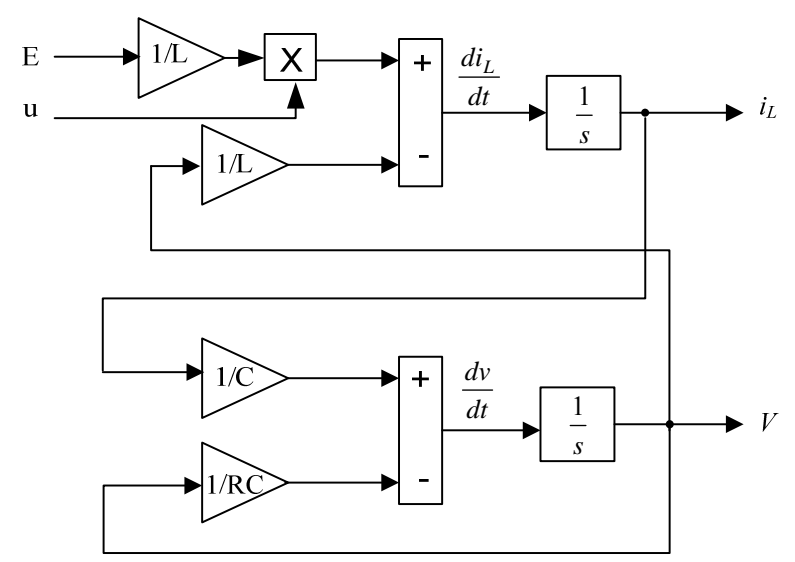

Figure 3. Block diagram of a buck converter. 
by a switching function. The theory of the sliding mode applied dc-dc converters and other areas can be found in references [12-15] and will not be given here. The main aim is to force the system states to the sliding surface, and the adopted control strategy must guarantee the system trajectory move toward and stay on the sliding surface from any initial condition as in Figure 4.

\section{Sliding Mode Controller Design}

In sliding mode, the control is discontinuous in nature. Here, the control switches at an infinite speed between two different structures. A sliding mode control system may be regarded as a combination of subsystems, each with a fixed structure and operating in a particular region of the state space. The sliding mode control design problem is to select parameters for each of the structure and define a switching logic.

Using the state equations given in Equations (1) and (2) and letting $x_{1}=i_{L}$ and $x_{2}=V$ as the new states of the system, the new state equations become

$$
\begin{gathered}
\dot{x}_{1}=\frac{E}{L} u-\frac{1}{L} X_{2} \\
\dot{x}_{2}=\frac{1}{C} X_{1}-\frac{1}{R C} X_{2}
\end{gathered}
$$

Generally, the control for dc-dc converters is to regulate the output voltage at desired level. Now the aim here is to obtain a desired constant output voltage $V_{d}$. The desired output is then $x_{1}{ }^{*}=V_{d} / R$. The task is to ensure the actual current $x_{1}$ tracks the desired current. That is, in steady state the output voltage should be the desired voltage $V d$. Thus,

$$
\begin{gathered}
x_{2}=V_{d} \\
\dot{x}_{2}=\dot{V}_{d}=0
\end{gathered}
$$

Sliding mode controller uses a sliding surface which ensures output voltage to go to desired value once the

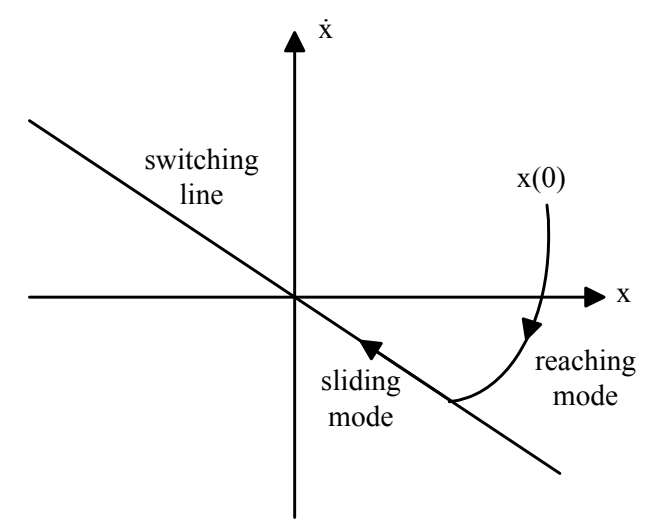

Figure 4. The modes of variable structure control systems. system gets onto the sliding surface. The state variables may be used to construct the sliding function. From the general sliding mode control theory, the state variable error, defined by difference to the reference value, forms the sliding function

$$
S=x_{1}-x_{1}^{*}=0
$$

This means that the control forces the system to evolve on the sliding surface [2]. The reference value $x_{1}{ }^{*}$ is derived internally to the controller from the output of the linear voltage controller.

In order to enforce sliding mode in the manifold $S=0$, the corresponding control signal for the ideal switch in Figure 1 is [12]

$$
u=\frac{1}{2}(1-\operatorname{sign}(S))
$$

Since the aim is to guarantee that the state trajectory of the system is directed to the sliding surface $S=0$ and slides over it, this is achieved with a suitable design of control law using the reaching condition

$$
S \dot{S}<0
$$

since

$$
\dot{S}=\dot{x}_{1}-\dot{x}_{1}^{*}
$$

The steady state values of state variables coincide with the corresponding reference values and they are constants then, replacing Equation (11) in Equation (13) and solving it we get

$$
0<x_{2}<E
$$

This means that the sliding mode exists if the output voltage is lower than the source voltage.

\section{Simulations}

In order to obtain a desired output voltage, the closedloop control is then necessary to maintain the output voltage even the input voltage has some variation. The analysis of the converter shows that the system dynamics can be divided into fast (current) and slow (voltage) motion. In this study two-loop control, an inner current control loop and an outer voltage control loop, is used. The voltage loop controller is a linear PI type with parameters of $K_{p}=50$ and $K_{I}=10$ controller. Since the motion rate of the current is much faster than that of the output voltage, a sliding mode controller is used in the inner current loop. A closed-loop control system for buck converter is designed and the block diagram of the overall system is shown in Figure 5.

Simulations were performed on a typical "buck" converter circuit with the following parameter values: $E=20$ $\mathrm{V}, L=40 \mathrm{mH}, C=4 \mu \mathrm{F}, R=40 \Omega$ (Table 1). 


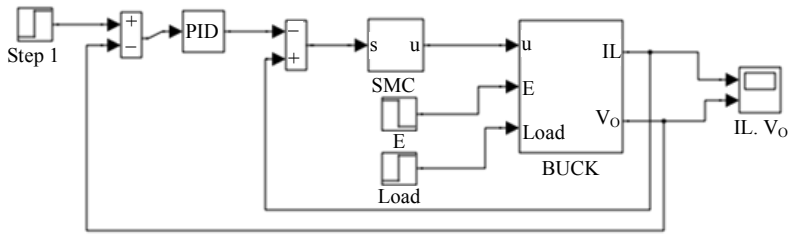

Figure 5. Simulink block of the closed loop control of buck converter.

Table 1. Converter parameters.

\begin{tabular}{cccc}
\hline$E(\mathrm{~V})$ & $L(\mathrm{mH})$ & $C(\mu \mathrm{F})$ & $R(\Omega)$ \\
\hline 20 & 40 & 4 & 40 \\
\hline
\end{tabular}

Figure 6 shows output voltage and current transient response during a change in the reference voltage from $10 \mathrm{~V}$ to $12 \mathrm{~V}$ at time $t=0.005 \mathrm{~s}$.

Generally speaking, sliding mode control is regarded as a robust feedback control technique with respect to matched unmodelled external perturbation signals and plant parameter variations.

In order to test the robustness of the sliding mode control scheme, the load resistor $R$ has been let undergo a sudden unmodelled and permanent variation of $50 \%$ of its nominal value of $40 \Omega$. This variation took place, approximately, at time, $t=0.003 \mathrm{~s}$, while the system was already stabilized to the desired voltage value of $10 \mathrm{~V}$ and, it takes the value of $25 \Omega$, at $t=0.006 \mathrm{~s}$.

Figure 7 shows the excellent recovering features of the proposed controller to the imposed load variation. As expected, the output voltage is robust when the load resistance was subject to a sudden unmodelled variation from $R=40 \Omega$ to $R=60 \Omega$ at time $t=0.003 \mathrm{~s}$, and from $R=60 \Omega$ to $R=25 \Omega$ at time $t=0.006 \mathrm{~s}$.

Figure 8 shows the performance of the sliding mode based control scheme, when the input voltage $E$ is changed from $20 \mathrm{~V}$ to $22 \mathrm{~V}$ at the time $t=0.003 \mathrm{~s}$ and from $22 \mathrm{~V}$ to $18 \mathrm{~V}$ at $t=0.006 \mathrm{~s}$, with a desired steady state output voltage of $10 \mathrm{~V}$.

Figure 7 and 8 allows to prove the robustness of the sliding mode control against changes in the load and variations in the input voltage.

The phase portrait can be seen in Figure 9 when reference voltage is $15 \mathrm{~V}$ and the load is $60 \Omega$. The controller makes the trajectory to form a stable limit cycle. The limit cycle width on the $V_{o}$-axis is equal to the voltage ripple seen on the output of the converter. In Figure 9, phase portrait is given.

The two phases of the dynamics can easily be observed in the figure. The states first reach the sliding surface and then are constrained to the sliding surface. Instead of sliding, the states fluctuate around the sliding surface. When the states reach to a close neighborhood
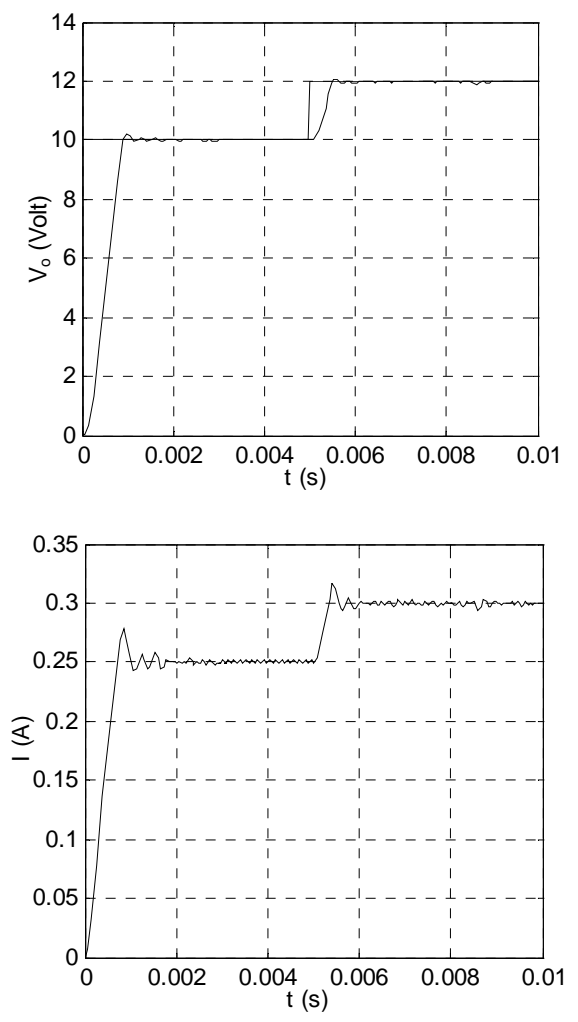

Figure 6. Output voltage and input current waveforms for step change in reference voltage.
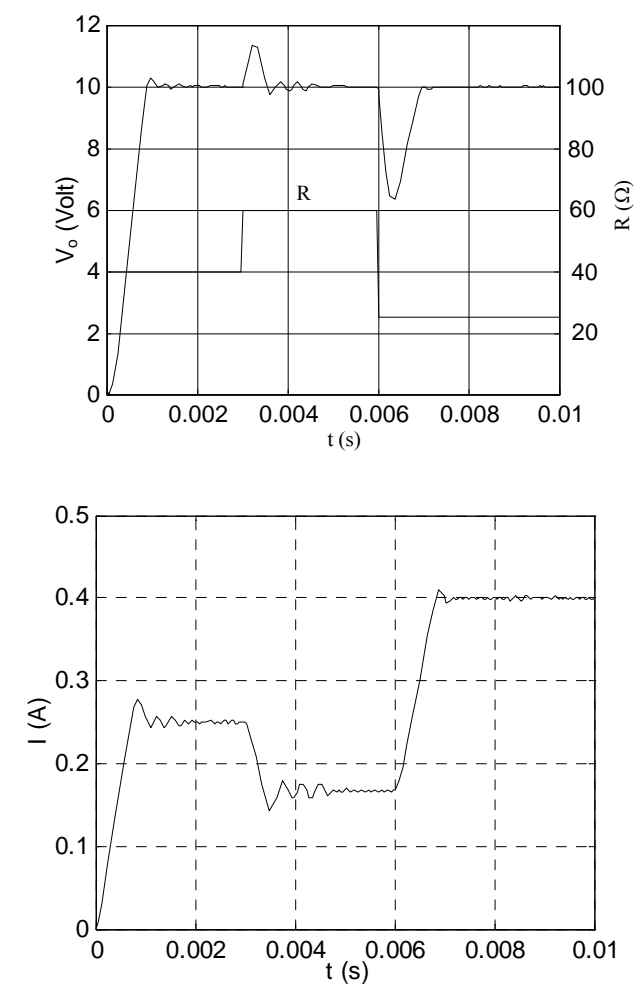

Figure 7. Output voltage and input current waveforms for step load variations. 

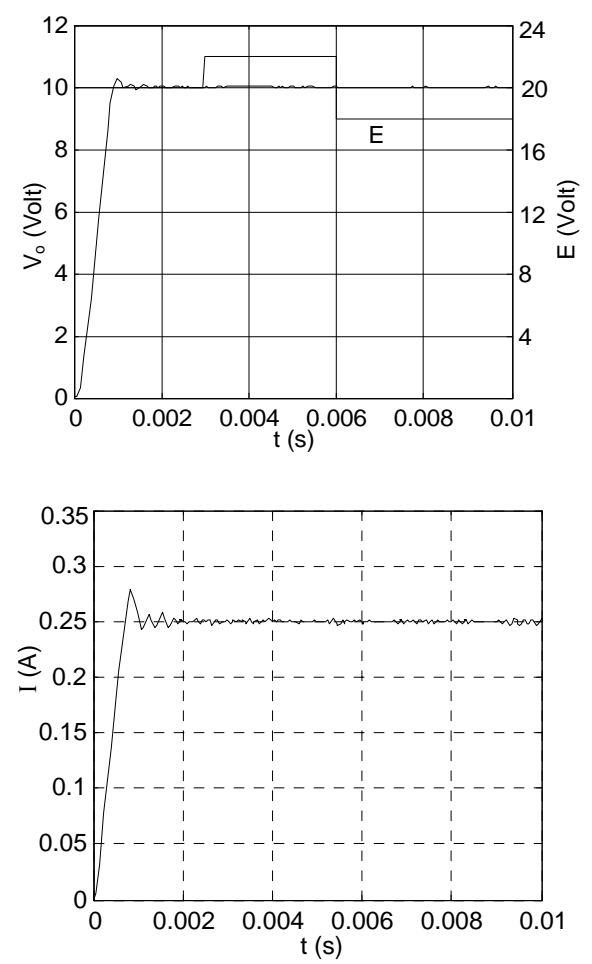

Figure 8. Output voltage and input current waveforms for step changes in input voltage.

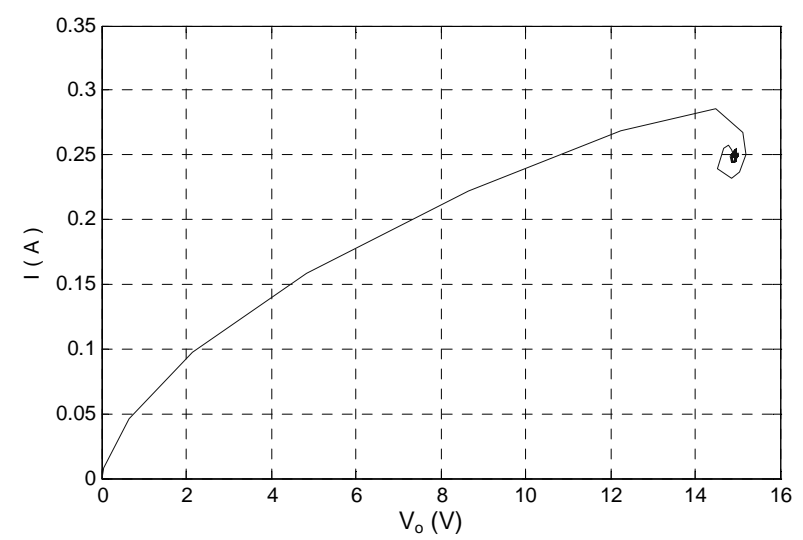

Figure 9. The phase portrait (output voltage vs current waveforms).

of the sliding surface they don't stay on the sliding surface, they continuously cross the sliding surface. This phenomenon is called chattering. This is due to the fact that control input is not in infinite frequency.

\section{Conclusions}

A dc-dc buck converter with sliding mode control is simulated in this study. It allows evaluation of closed loop performances like tracking the desired output voltage. The simulation results show the validity of the slid- ing mode controlled buck converter model and the robustness of this control technique against changes in the load or variations in the input voltage. Therefore the system achieves a robust output voltage against load disturbances and input voltage variations to guarantee the output voltage to feed the load without instability. Robustness and good dynamic behavior is achieved even for large supply and load variations.

\section{References}

[1] A. J. Forsyth, "Modeling and Control of DC-DC Converters," Power Engineering Journal, Vol. 12, No. 5, 1998, pp. 229-236. doi:10.1049/pe:19980507

[2] P. Mattavelli, L. Rosetto and G. Spiazzi, "Small-Signal Analysis of Dc-Dc Converters with Sliding Mode Control," IEEE Transactions on Power Electronics, Vol. 12, No. 1, 1997, pp. 96-102. doi:10.1109/63.554174

[3] J. Matas, L. G. Vicuna, O. Lopez, M. Lopez and M. Castilla, "Sliding-LQR Based Control of Dc-Dc Converters," European Power Electronics Conference (EPE'99), Lausanne, 7-9 September 1999.

[4] G. Spiazzi and P. Mattavelli, "Sliding Mode Control of Switched-Mode Power Supplies," CRC Press LLC, Boca Raton, 2002.

[5] O. Kaynak and F. Harashima, "Disturbance Rejection by Means of Sliding Mode," IEEE Transactions on Industrial Applications, Vol. 32, No. 1, 1985, pp. 85-87.

[6] Y. He and F. L. Luo, "Sliding-Mode Control for Dc-Dc Converters with Constant Switching Frequency," Control Theory and Applications, Vol. 153, No. 16, 2006, pp. 3745.

[7] Z. H. Akpolat and H. Guldemir, "Trajectory Following Sliding Mode Control of Induction Motors," Electrical Engineering, Vol. 85, No. 4, 2003, pp. 205-209. doi:10.1007/s00202-003-0166-6

[8] H. Guldemir, "Sliding Mode Speed Control for Dc Drive Systems," Mathematical and Computational Applications, Vol. 8, 2003, pp. 337-384.

[9] H. Guldemir, "Sliding Mode Control of Dc-Dc Boost Converter," Journal of Applied Sciences, Vol. 5, No. 3, 2005, pp. 588-592

[10] J. J. Slotine and T. S. Liu, "Applied Nonlinear Control," Prentice Hall, Englewood Cliffs, 1991.

[11] J. Y. Hung, W. Gao and J. C. Hung, "Variable Structure Control: A Survey," IEEE Transactions on Industrial Electronics, Vol. 40, No. 1, 1993, pp. 2-21. doi:10.1109/41.184817

[12] V. Utkin, J. Guldner and J. Shi, "Sliding Mode Control in Electromechanical Systems," Taylor and Francis, London, 1999.

[13] V. Utkin, "Sliding Mode Control Design Principles and Applications to Electric Drives," IEEE Transactions on Industrial Applications, Vol. 40, 1993, pp. 23-36.

[14] J. H. Su, J. J. Chen and D. S. Wu, "Learning Feedback 
Controller Design of Switching Converters via Matlab/ Simulink," IEEE Transactions on Education, Vol. 45, 2002, pp. 307-315. doi:10.1109/TE.2002.803403

[15] H. Sira-Ramirez, "On the Generalized PI Sliding Mode
Control of DC to DC Power Converters: A Tutorial," International Journal of Control, Vol. 76, No. 9, 2003, pp. 1018-1033. 